\title{
ÁFRICA NEGRA EN LOS LIBROS DE VIAJES ESPAÑOLES DE LOS SIGLOS XVI Y XVII
}

\author{
ANTOINE BOUBA KiDAKOU \\ kidakou@yahoo.fr
}

\section{RESUMEN}

Los siglos XVI y XVII estuvieron marcados especialmente por una considerable expansión oceánica, y por una explosión de la empresa viajera como resultado de esa expansión. Además de los peregrinos, mercaderes, embajadores y caballeros que ya recorrían diferentes partes del mundo desde la Edad Media, los exploradores, los conquistadores y los misioneros venían a alargar la lista de los viajeros y, generalmente, dejaban testimonio escrito de sus experiencias. Este artículo pretende contribuir al conocimiento de los relatos de viajes españoles de los siglos XVI y XVII sobre el África negra, una zona geográfica que apenas aparece en las fuentes por las que se han interesado los filólogos hasta este momento. En los relatos de viajes que constituyen el corpus seleccionado se analizan los contenidos de los principales mensajes que se transmiten sobre los Negros. Nos interesamos sobre todo por la manera cómo los autores hacen la representación del Negro y de su espacio, y se cotejan las diferentes posturas adoptadas por los escritores a la hora de describir la realidad negra. En este sentido, se ha observado una dicotomía entre la postura despectiva y la visión totalizadora que marcaron el estilo de los viajeros del siglo XVI y el procedimiento sociológico que adoptaron los autores de relatos de viajes del siglo XVII en su representación de las realidades negras. Además, se ha notado la singularidad de una región del África negra, Etiopía, que llamó más la atención de los viajeros, al convertirse prácticamente en el principal destino de los viajeros españoles del siglo XVII, por varios motivos relacionados con la particularidad de la historia sociopolítica y religiosa del pueblo abisinio y el mito del Preste Juan de las Indias. Por fin se apunta la necesidad de muchos estudios particulares sobre los libros de viajes españoles del Siglo de Oro sobre el África negra para investigar con profundidad 
muchos aspectos de señalado interés filológico apuntados en el artículo, o para extender el estudio a los relatos de viajes que se han quedado fuera del corpus seleccionado para este trabajo.

Palabras Claves: Literatura de viajes en el Siglo de Oro; viajeros españoles en el África negra; percepción y expresión de la realidad negra; culturas en contacto.

\section{ABSTRACT}

The XVI ${ }^{\mathrm{th}}$ and $X V I^{\mathrm{th}}$ centuries were particularly significant for the western people's maritime opening in general and especially for the Iberian Peninsula, leading to an explosion of travel activities. Besides the pilgrims, the traders, the ambassadors and knights errant who had already travelled through many parts of the world since the Middle Ages, the conquerors and the missionaries had lengthened the list of these travellers. After or during their voyage, they generally left written evidences of their experiences. However, these travel books remain little attended by literary critics and, one of the main objectives of this article is to contribute to the best knowledge of some aspects of the Spanish Golden Age travel literature which is not related to Latin America. The main purpose here is to lay emphasis on the existence of some Spanish Golden Age travel accounts on the Black Africa, a geographical zone which is scarcely mentioned in the travel books generally attended by critics. One of the main aims, in the selected travel accounts is to analyse the ways the representation of the black people and their space was done by these eyewitnesses. In the end, one of the remarkable facts pointed out is the dichotomy between the disdainful position and global vision of the XVI ${ }^{\text {th }}$ century travellers and the much more sociological procedure of those of the XVII ${ }^{\text {th }}$ century, in their ways of describing black realities. Another interesting observation is the unequal distribution of these accounts in the black African space: most of these travel accounts were written on the kingdom of Abyssinia, which was the main destination of the Iberian travellers, due to historical, cultural and religious reasons. Finally, we point out the needs of many specialized studies on the Golden Age travel accounts on Black Africa to fill the gap in the Spanish literature on the issue.

KEY Words: Travel literature in the Golden Age; spanish travellers in Black Africa; perception and description of black realities; cultures in contact.

\section{INTRODUCCIÓN}

Este trabajo es el resultado de las principales conclusiones de mi tesis doctoral, África negra en los libros de viajes españoles de los siglos XVI y XVII, en la que se estudian los relatos de viajes escritos por viajeros españoles sobre esa zona geográfica en el Siglo de Oro. Una de las principales motivaciones en la elección de este tema es la temprana presencia de muchos españoles o peninsulares en tierras de los Negros aun antes del descubrimiento de América, presencia que se mantuvo después, ya que los españoles 
no abandonaron el espacio geográfico negro-africano, aunque el interés por él había decrecido. Esa presencia supone la existencia de fuentes documentales donde quedan plasmadas sus experiencias y en las que se reflejan sus percepciones del Negro y de su espacio. Sin embargo, faltan estudios relevantes o de conjunto sobre este aspecto de la literatura española hasta hoy, pues sólo existen aproximaciones a algunos elementos específicos. Cabe precisar de antemano que el criterio fundamental que se ha aplicado para la selección de los relatos de viajes examinados en este trabajo es que el viaje se haya realizado exclusivamente a algún país o reino del África negra. Por tanto quedan descartados del corpus aquellos libros en los que el África negra aparece sólo como una etapa en un itinerario que tiene un destino diferente. El trabajo no tiene, por tanto, la pretensión de abarcar todos los relatos de viajes que hacen alguna mención al África negra, sino la más modesta de presentar los relatos representativos sobre esa área geográfica.

Conviene también empezar por una observación: la escasez de los relatos de viajes del Siglo de Oro sobre el África negra. En efecto, tras la revisión de las fuentes bibliográficas fundamentales ${ }^{1}$, se puede afirmar que el panorama de la bibliografía de los libros de viajes de los siglos XVI y XVII sobre esa región es poco halagüeño. Además, la bibliografía crítica de esos relatos es prácticamente inexistente, quizá porque el corpus de los relatos de viajes del Siglo de Oro está poco atendido en general, en relación con la importancia de esos escritos, sobre todo en comparación con los trabajos de conjunto existentes sobre los relatos de viajes de la Edad Media, o sobre los relatos de los siglos XVIII y XIX. Por otra parte, se puede observar que dentro del corpus de los relatos del Siglo de Oro sobre el continente africano, los relatos sobre la tierra de los Negros son poco numerosos en comparación con los relatos sobre el África mediterránea, pero lo más sorprendente, con todo, es la carencia de estudios críticos sobre esos relatos de viajes de tema negro-africano, como ya se ha señalado anteriormente. Así pues, la revisión de las fuentes bibliográficas generales y especializadas permite descubrir la existencia de un gran número de libros de viajes españoles del Siglo de Oro sobre el continente africano, pero la distribución geográfica de esos relatos sobre este continente es muy desigual. Al tomar como referencia las obras de Miguel Ángel de Bunes Ibarra, y de Mercedes García Arenal en colaboración con Miguel Ángel de Bunes, se puede notar que se recogen doscientos ochenta y siete relatos sobre el África del norte, mientras que la suma de todos los relatos de viajes escritos sobre viajes realizados exclusivamente al África negra (y bien reflejado en sus títulos) es inferior a dieciséis. ${ }^{2}$

Las causas de esa aparente marginación del África negra en los relatos de viajes españoles de los siglos XVI y XVII podrían relacionarse con el descubrimiento de América y el desplazamiento de gran parte del centro de interés económico y cultural que siguió

\footnotetext{
${ }^{1}$ Algunas de las principales fuentes bibliográficas existentes sobre los relatos de viajes del Siglo de Oro en España son las obras de C. García Romeral Pérez: Bio-bibliografía de viajeros españoles: Siglos XVI y XVII, Madrid: Ollero y Ramos, 1999 y Diccionario de viajeros españoles: desde la Edad Media a 1970, Madrid: Ollero y Ramos, 2004; V. Herrero Mediavilla, y L. Aguayo Nayle, Índice biográfico de España, Portugal e iberroamérica, Paris: Saur, 1990 y D. Barbosa Machado, Bibliotheca Lusitana historica, critica e cronologica: na qual se comprehende a noticia dos autores portugueses...desde o tempo da promulgação da ley de graça até o tempo prezente, Lisboa: Officina de Antonio Isidoro da Fonseca, 1747.

${ }^{2}$ M. A de Bunes Ibarra, La imagen de los musulmanes y del Norte de África en la España de los siglos XVI y XVII, Madrid: CSIC, 1989; M García y M. A. de Bunes, Repertorio bibliográfico de las relaciones entre la Península Ibérica y el Norte de África (siglos XV-XVI), Madrid: CSIC, 1989.
} 
ese descubrimiento. Pero ese elemento no era el único que podía justificar esa falta de interés por registrar por escrito las experiencias de los viajeros españoles en el África negra. Al contrario del África del norte, por ejemplo, donde se concentraban los intereses políticos y económicos, y que requería una descripción detallada por razones obvias de estrategia político y militar, se notó en el África negra la falta de ese mismo interés geoestratégico, al estar esos territorios lejos del ámbito de las aspiraciones expansionistas del imperio musulmán de los otomanos, gran rival de la monarquía hispánica. Ese factor hizo probablemente que el África negra llamara menos la atención de los escritores, a pesar de la presencia bastante temprana y numerosa de los peninsulares en esa zona por razones variadas como pudieran ser el comercio de metales preciosos, el oro y el diamante, y sobre todo el comercio de esclavos.

\section{Relación y CONTENidos de los libros de Viajes del Siglo de Oro SOBRE EL ÁFRICA NEGRA}

\subsection{Relación de los relatos de viajes}

Juan León el Africano, Descripción general de África y de las cosas peregrinas que allí hay, Roma: Ramusio, $1550 .^{3}$

Tomás de Barros, Copia de una carta que escrivió el padre Tomás de Barros de la Compañía de Iesus en Iunio de 622 al padre General, en que declara lo que los de la Compañía hizieron en el imperio de Etiopía, en el dicho año de $622^{4}$

Antonio Fernández, Copia de una del padre Antonio Fernández, Superior de las casas que la Compañía de Jesús tiene en el imperio de Etiopía, escrita en Dancas, corte del emperador de los abexinos en 11 de iunio de 1626, a su procurador en esta corte, del recibimiento que aquel emperador hizo al patriarcha católico, y de la reducción de aquel imperio a la iglesia romana, $1627^{5}$.

Luis del Mármol Carvajal, Descripción general de Áffrica: Primera Parte, $1573 .{ }^{6}$

-Segunda parte y libro séptimo de la descripción general de Áffrica, donde se contiene las provincias de Numidia, Libia, la tierra de los Negros, la baxa y la alta Etiopía, Egipto, con todas las cosas memorables della, $1599 .{ }^{7}$

Diego de Matos, Copia de una carta que el padre Diego de Matos de la Compañía de Iesus escrive al padre General de la misma Compañía, en que da quenta a su paternidad del estado de la conversión a la verdadera religión christiana católica romana, del

\footnotetext{
${ }^{3}$ Redactada en 1526, la obra no se publicó hasta 1550, cuando Gian Battista Ramusio la sacó a luz. El título original es Della Descrittione dell' Africa e delle cose notabili che ivi sono. La primera traducción española, anónima e incompleta, es de 1940. La traducción que se ha manejado para este trabajo es la de Serafín Fanjul, Barcelona: Lunwerg, 1995.

${ }^{4}$ Se desconocen el lugar y la fecha de publicación de esa carta. Pero Barbosa Machado afirma que esa carta fue traducida al italiano en 1627 por el Padre Francisco Corbelletti, y al francés por el Padre João en 1628

${ }^{5}$ Este relato se imprimió en Madrid, por la Viuda de Luis Sánchez en 1627.

${ }^{6}$ La primera edición es la de Granada: René Rabut, 1573. Se ha manejado la edición facsímil del Instituto de Estudios Africanos del Patronato Diego Saavedra Fajardo del Consejo Superior de Investigaciones Científicas, 1953.
}

${ }^{7}$ No existe edición moderna de esta segunda parte que apareció en Málaga en casa de Iuan René, 1599. 
gran imperio de Etiopía, cuyo emperador es el Preste Juan, escrita en la ciudad de Fremona, su fecha en veinte de iunio de $1621^{8}$

Pedro Páez Jaramillo Copia de una carta del padre Pedro Páez de la Compañía de Jesús, escrita en Etiopía por Iulio del año passado, para un padre de la misma Compañía de la Provincia de Toledo. En la qual le da cuenta de cómo el emperador de aquel reyno se a buelto cristiano, y de una gran vitoria que alcançó de un hermano suyo, que le quería matar por aver dexado entrar el Santo Evangelio en sus tierras, 1619.

-Copia de una del padre Pedro Páez de la Compañía de Iesus, escrita en Etiopía a 6 de iulio de 617 para un padre de la provincia de Toledo de dicha Compañía, [s. n] ${ }^{9}$

José Pellicer de Ossau Salas y Tovar, Mission evangelica al reyno de Congo por la Seráfica religión de los capuchinos, $1649 .{ }^{10}$

Juan de Baltasar Abissino, Fundación, vida y regla de la grande orden militar y monástica de los cavalleros y monjes del glorioso padre san Antón Abad, en la Etiopía, Monarchia del Preste Juan de las Indias, $1609 .{ }^{11}$

Francisco Alvares, Verdadeira informaçam das terras do Preste João das Indias, $1889 .{ }^{12}$

Manoel d'Almeyda, Historia de Ethiopia a alta ou Abassia, imperio do Abexim, cujo Rey hé chamado Preste Joam, composta pelo padre Manoel d'Almeida da Companhia de Jesus, natural de Viseu, 1611.

Baltasar Tellez,, Histoira geral de Ethiopia a Alta ou Abassia do Preste Ioam, e do que nella obraram os padres da Companhia de Iesus: composta no mesma Ethiopia, pelo padre Manoel d'Almeyda, natural de Viseu, Provincial, e Visitador, que foy na India. Abreviada como nova releyçam, e methodo pelo padre Balthazar Tellez, natural de Lisboa, Provincial da Provincia Lusitana, ambos da mesma Companhia, 1660.

Pero Pais, Historia de Etiópia, 1622. ${ }^{13}$

Luis de Urreta, Historia eclesiástica, política, natural y moral de los grandes y remotos reynos de Etiopía, Monarchia del Emperador, llamado Preste Juan de las Indias. Muy útil y provechosa para todos estados, principalmente para predicadores. A la sacratísima y siempre Virgen María del Rosario. Compuesta por el Presentado Fray Luis de Urreta, de la Sagrada Orden de Predicadores, 1610.

${ }^{8}$ Este relato se imprimió en Madrid por Luis Sánchez en 1624 y no existe edición moderna, como es también el caso de los relatos de Diego de Matos, Antonio Fernández y Tomás de Barros.

${ }^{9}$ La primera carta de Pedro Páez, se publicó en Sevilla, por Francisco de Lira en 1619, pero se desconoce la fecha exacta de la publicación de la segunda. No existen ediciones modernas de esas cartas.

${ }^{10}$ El relato de Pellicer de Tovar es el más extenso del siglo XVII sobre el África negra. Aunque la historia del relato se basó en la misión de los capuchinos en el reino del Congo, es la única obra cuyo autor es seglar. Se publicó en Madrid por Domingo García Morrás en 1649 y no existe ninguna edición moderna. Precisemos que Pellicer de Tovar es un autor poco conocido a pesar de que fue un escritor prolífico (su obra constancia de más de doscientos libros) y un notable político (fue Cronista Mayor del reino de España)

${ }^{11}$ Por el origen de su autor, se puede considerar la obra de Juan de Baltasar Abssino como una réplica africana a las obras occidentales sobre la Etiopía del siglo XVII. Se publicó en Valencia en 1609 y no existe ninguna versión moderna.

${ }^{12}$ La edición manejada en este trabajo es: F. Álvares, Verdadeira informação das terras do Preste João das Indias, Introdução e notas de Neves Águas, Lisboa: Europa-América, 1989. Esta obra se considera como una de las principales fuentes del siglo XVI sobre el África negra, por su riqueza documental.

${ }^{13}$ Escrita en 1622, esta obra no se editó hasta el año 1945, cuando Elaine Sanceau la sacó a luz en Lisboa: Livraria \&Civilização, con una extensa nota introductoria de la editora. 
-Historia de la sagrada Orden de los predicadores en los remotos reynos de la Etiopía. Trata de los prodigiosos Santos, Mártyres, y Confessores, Inquisidores apostólicos, de los conventos puritanos, donde viven nueve mil frayles del alleluya con siete mil de los Bedenagli, de cinco mil monjas, con otras grandezas de la religión del padre santo Domingo, 1611.

\subsection{Contenidos de los relatos de viajes del Siglo de Oro sobre el África negra}

Los contenidos de estos libros no se salen de la tradición de los libros de viajes vigente ya en la Edad Media: la principal materia contenida en las informaciones se enmarca en los campos de la historia y la geografía. Pero además de las informaciones de carácter histórico, geográfico o antropológico, se puede notar también la hábil puesta en escena de episodios históricos, la voluntad de consignar los hechos considerados relevantes por esos viajeros, con la inevitable integración de mitos y fabulaciones; aspectos que confirman la relativa importancia documental (o histórica) de esos relatos. Al mismo tiempo, todos esos aspectos contribuyen a la dimensión literaria de esos escritos. Sin embargo, cabe señalar que al cotejarlos en muchos aspectos, los contenidos de esos relatos de viajes dejan aparecer algunas diferencias fundamentales en el tratamiento del espacio y de la imagen del Negro, y esas diferencias se expresan sobre todo en términos de ruptura. Se podría remontar hasta un siglo atrás para señalar la primera ruptura: la que se puede observar entre los viajeros españoles del siglo XVI y los viajeros europeos anteriores a ellos. Esa diferencia se nota sobre todo en la manera de recoger y presentar las informaciones sobre el África negra. Muchos autores del siglo XV intentaban recabar todas las informaciones (geográficas, históricas, políticas y culturales) sobre las tierras y los habitantes del África negra y, por ello, no sólo describían lo que observaban sino que intentaban buscar las causas de los fenómenos que presenciaban. Al final de ese proceso ofrecían un conjunto de informaciones históricas, antropológicas y geográficas en las que iban a basarse los posteriores exploradores. Una muestra de esa actitud inquisidora y analítica de los primeros viajeros europeos al África negra ha sido recogida por Russell en un importante estudio sobre el tema. ${ }^{14}$ Tanto el relato de Antonio de Usidimare como los de Pedro de Cintra y Eustache de La Fosse citados por Russell proporcionaron a los mercaderes y exploradores datos de primera mano sobre las realidades negras: aspecto físico, características de su religión y de sus tierras, así como el papel que jugaba el negro en el comercio de las especias.

En cuanto a la ruptura entre los autores de relatos de viajes del siglo XVI y los del siglo XVII, un examen más detenido de los aspectos fundamentales de esa ruptura es necesario.

\subsubsection{Los relatos de viajes del siglo XVI}

Los dos relatos del siglo XVI examinados en este estudio ${ }^{15}$ marcaron, en su contenido temático sobre los negros, una diferencia muy importante con los precedentes.

\footnotetext{
${ }^{14}$ P.E. Russell, «Veni, vidi, vici: some fifteenth century eyewitness accounts of travel in the African Atlantic before 1492» en Historic Research LXVI (June 1993), p. 117.

${ }^{15}$ J. L. el Africano, Descripción general de África, op. cit; L. del Mármol Carvajal, Descripción general de Áffrica, op. cit.
} 
Primero, porque el África negra no constituía el tema central o específico de esas obras. Esa región apenas ocupa una proporción estimada en una cuarta parte en las obras de Juan León el Africano y Luis del Mármol Carvajal. Además de ese tratamiento, el aspecto más llamativo en esas obras es la manera peculiar en que ambos autores hacen la representación del Negro y de su espacio: la reproducción en tierras africanas de mitos de la antigüedad y medievales relacionados con puntos geográficos de gran significado tuvo una profunda influencia en la descripción que de la realidad de esa región hicieron Juan León el Africano y Luis del Mármol Carvajal en sus obras. ${ }^{16}$ Sin lugar a dudas, el tratamiento de la información sobre los Negros y la elaboración de las imágenes de esa región del continente han tenido fuertes influencias exteriores a los autores. Sabiendo que para muchos europeos de la Edad Media los motivos insulares y de tierras muy lejanas constituyeron bastiones territoriales y geográficos que ofrecían el emplazamiento físico necesario para todo un mundo de prodigios y de seres fantásticos, esos autores no podían romper de manera repentina con esa tradición, y por tanto no se salieron de los caminos trillados. Así, el África negra se convertía en una fábula para esos viajeros y el viaje, por real que pudiera ser, era ante todo un texto, o mejor dicho, una organización histórica y cultural en el trasfondo de un sistema de signos cuyo proceso de puesta en escena y de descodificación por el lector se encontraba asociado al mecanismo de producción del sentido. Esos aspectos de los relatos de Juan León el Africano y Luis del Mármol Carvajal transformaban los viajes realizados por sus autores al África negra en actividades referenciales y los espacios descritos se convertían también en lugares referenciales. El espacio negro-africano objeto de la mirada del sujeto descriptor era ya una realidad definida mucho tiempo antes de la realización del viaje. En este sentido, la observación, la descripción o la representación de esos espacios no eran más que una reestructuración escrita de algo que se había conceptualizado mentalmente antes: una relación del referente producida en el marco de una ficcionalización intensa regulada por los conocimientos que el Occidente poseía o creía poseer sobre el mundo conocido y sobre las formas deducibles de las tierras desconocidas. Pero también, recalquemos, se trataba para esos autores, de evitar cualquier tipo de revolución profunda y brusca dentro del estereotipo funcional de la sociedad.

Sin embargo, ambos escritores sentían la necesidad de operar pequeños cambios, tales como la mención de los nombres de varios reinos negros por Juan León el Africano ${ }^{17}$ o la ampliación de la geografía negroafricana por Luis del Mármol Carvajal ${ }^{18}$ que, desde este punto de vista fue un éxito, pero había sobre todo que confirmar la conformidad de sus observaciones con la «erudición» de aquel entonces sobre los negros y sus territorios. Así, sus viajes pasaban de ser descubrimientos a convertirse en la confirmación de las fuentes preexistentes sobre esas realidades. Las exigencias del destinatario orientaron, desde luego, las plumas de esos autores y, más que una mirada o una descripción ideo-

\footnotetext{
${ }^{16}$ Sobre los aspectos maravillosos o míticos de las obras de Juan León y de Luis del Mármol Carvajal sobre el Negro y su espacio, remito a mi tesis, África negra en los libros de viajes españoles..., op. cit., pp 112-133 y 160-168.

${ }^{17}$ J. L. el Africano, op. cit, pp. 63, 82, 83, 86, 290-298.

${ }^{18}$ L. del Mármol Carvajl, Segunda parte y libro séptimo de la descripción general de Áffrica, donde se contiene las provincias de Numidia, Libia, la tierra de los Negros, la baxa y la alta Etiopía, Egipto, con todas las cosas memorables della, op. cit, Libros IX y X.
} 
lógica de los Negros por ellos mismos, se trataba, en las excesivas deformaciones que han sufrido el espacio y el hombre negro en sus obras, de una adecuación de la escritura al horizonte de expectativas del lector europeo. Por todo ello, Descripción general de África y de las cosas peregrinas... de Juan León el Africano y Descripción general de Áffrica de Luis del Mármol Carvajal distan de ser testimonios eminentemente documentales sobre los paisajes, los pueblos, las culturas y los gobiernos de las tierras de los Negros supuestamente recorridas por esos viajeros. Sea por adecuación de los contenidos de sus obras al contexto social e intelectual de su época en Occidente o por otro motivo, en su estancia en las tierras negras Juan León el Africano y Luis del Mármol Carvajal no quisieron tomar en cuenta (como fue el caso cuando describían el Norte de África en los mismos libros) que todos los pueblos tienen una vida sociocultural y política de extraordinaria complejidad, y que las circunstancias ocasionales de tiempo y lugar que influyen en sus actividades crean muchas variaciones en sus manifestaciones. No parecían haberse tomado el tiempo suficiente ni la curiosidad de decodificar las realidades de la cultura y de la sociedad negra. Por ello se detuvieron en las apariencias accidentales, sin entrar en los estratos esenciales y permanentes de su personalidad, los resortes íntimos que les movían en sus acciones y toda la complejidad que subyace a las raciales características que afloran a la superficie. Por otra parte, las exigencias del público lector ya mencionado, más versadas en los aspectos sensacionalistas, fantásticos y maravillosos, habrían influido tanto en esos escritores que suplieron la falta de informaciones de primera mano por largos excursos en el mundo de esas realidades exóticas y fantásticas. Las informaciones fidedignas se encuentran diluidas en esas profusas maravillas que dominan los relatos.

\subsubsection{Los relatos de viajes del siglo XVII}

En cuanto a los relatos de viajes del siglo XVII, sus autores eran casi todos religiosos. Sus viajes al África negra, aunque contribuyeron mucho a la historia de las exploraciones de tierras desconocidas, no estaban motivados prioritariamente por el afán de descubrimiento. Por tanto no extraña que sus relatos se ajusten a los objetivos de sus viajes: difundir la religión cristiana en el mundo, informar a sus superiores sobre el estado de la espiritualidad de las poblaciones de las tierras de misión y sobre el desarrollo de sus misiones. Todo ello explica sus peculiaridades frente a los demás relatos de viajes.

Sin embargo, cabe clasificar esos relatos del siglo XVII en dos sub-categorías, aunque sus argumentos comunes se construyeron en torno al desarrollo de las actividades misioneras. Por un lado, los relatos de los religiosos escritos por ellos mismos, que se caracterizan por su brevedad (porque consisten en cartas principalmente) y una actitud peculiar frente a la realidad negra. En sus relatos, los religiosos, independientemente de sus órdenes, mantuvieron una actitud distante y precavida frente a las manifestaciones de la cultura negra, absteniéndose principalmente de emitir ciertos juicios de valor sobre ellas, excepto cuando éstas obstaculizaban demasiado la realización de su misión en el terreno. En este último extremo, los aspectos denunciados por todos esos religiosos son la poligamia, la hechicería, y las formas en que se celebraban las ceremonias de los funerales. Esa distancia se manifiesta en las obras de los misioneros desde distintas perspec- 
tivas, incluyendo omisiones de referencias culturales fuera de las prácticas espirituales o de los elementos estrictamente relacionados con la religión. No aparecen en sus escritos las descripciones de los rasgos horribles y fantásticos atribuidos a esos pueblos, ni en sus aspectos físicos, ni en sus manifestaciones sociales. La ausencia de ciertos aspectos sensacionales y maravillosos en la escritura de los misioneros en su conjunto podría explicarse por dos factores fundamentales: se trataba de una actividad estatutaria (el caso de los jesuitas lo ilustra perfectamente) regida por unas normas precisas. Así pues, enviar informaciones a los superiores y a otros compañeros se consideraba como la prolongación de sus misiones, en la medida en que esos escritos debían servir como guía espiritual de los fieles y puente que mantenía el lazo y la comunicación entre los compañeros de la misma orden ${ }^{19}$. Además, esos escritos constituían una fuente para el estudio de las expediciones apostólicas en sus respectivos períodos, y a este respecto, hablando de las cartas de los jesuitas, escribía Federico Palomo:

...fueron durante mucho tiempo casi el único instrumento de difusión de los modelos de acción característicos de la actividad misionera dentro de los territorios de la Península Ibéri$\mathrm{ca}^{20}$

Escritos en su gran mayoría durante el desarrollo de sus misiones, esos relatos eran principalmente testimonios de sus actividades y de su vocación y compromiso al servicio de Dios y del Hombre. El envío de esos escritos desde las lejanas tierras de misión modelaba la vocación de los jóvenes y de toda la sociedad en general, a la vez que constituían un dispositivo memorístico y de propaganda sobre el que se debía construir y fijar una determinada imagen de la orden.

En sus aspectos formales, los relatos de los misioneros no se salen de los patrones contenidos en las instrucciones que algunas órdenes daban para la elaboración de las cartas. Inés Zapunov, en un interesante estudio sobre las formas comunes de las correspondencias de los religiosos en las tierras de misión ${ }^{21}$, precisaba que esos escritos reproducían modelos de acción apostólica y de perfección religiosa, a la vez que pretendían guiar u orientar la conducta de los misioneros y de los fieles. Así, la buena impresión sobre la labor de los misioneros, las relativas facilidades en la conversión de los infieles son unas de las características relevantes de la escritura epistolar misionera en general y jesuítica en especial, y este aspecto se puede comprobar en los relatos de viajes escritos por los misioneros sobre el África negra. En cuanto a los modos de esa escritura, Inés Zapunov señala cuatro en las cartas de los jesuitas, y se han podido detectar esas modalidades en los relatos de los misioneros analizados en este trabajo:

\footnotetext{
${ }^{19}$ Sobre estos aspectos de los relatos de los misioneros en general y de los jesuitas en especial, remito a F. Torres Londoño, «Escrevendo Cartas. Jesuitas, escritura e Missão no século XVI» en Revista Brasileira de Historia, 43 (2002), pp. 17-18; J. Reverte, op. cit., pp. 43-44; S. Leite, Cartas dos primeiros jesuitas do Brasil, São Paulo: Comissão do IV Centenario da Cidade de São Paulo, 1954, vol. I, pp. 61 y ss; A. Boucher, Historia de los jesuitas... op. cit., passim.

${ }^{20}$ F. Palomo, «De algunas cosas que sucedieron estando en misión. Espiritualidad jesuita y escritura misionera en la Península Ibérica (siglos XVI-XVIII)» en A Compañía de Jesús na Peninsula Iberica nos seculos XVI e XVIII, Actas do Coloquio Internacional, Porto: Humbertipo, 2004, p. 123.

${ }^{21}$ I. Zapunov, Disputed Mission. Jesuit Experiments and Brahmanical Knowledge in Seventeenth-century India, New-Delhi, 1999, passim.
} 
-El modo teatral, que consiste en la escenificación de conversiones relevantes, de curaciones milagrosas, de expurgaciones del demonio de un cuerpo poseído, persecución de los religiosos por los infieles o pecadores y reacción maravillosa de Dios y de los santos a favor de los misioneros. Es muy común, tanto en los relatos de los jesuitas sobre los etíopes como en el de los capuchinos sobre el reino del Congo. El padre Pedro Páez atribuía al milagro divino la victoria del emperador etíope sobre los cismáticos encabezados por un general de su propio ejército y que contaba con el apoyo de numerosos capitanes del mismo ejército, porque la ventaja del número la llevaba ese ejército rebelde. Concluía el misionero el relato de ese suceso con las siguientes palabras: reino. ${ }^{22}$

...y desta suerte acabó derribado con una piedra el más arrogante capitán que avía en este

Diego de Matos no encontraba otra explicación sino en el milagro de Dios, para explicar el buen trato que recibieron, su compañero de viaje y él, de parte de los enemigos de su religión en tierras árabes mientras iban a Etiopía. ${ }^{23}$ La conversión de Asachristos, hermano del emperador etíope, en una ceremonia multitudinaria, así como la conversión de varias personalidades importantes del imperio en circunstancias similares, han sido presentadas como obras milagrosas divinas. Las curaciones milagrosas y salvaciones en situaciones de peligros pronunciados han sido bien aprovechadas tanto por Diego de Matos en su relato como por Antonio Fernández.

Este último describe con mucho detalle el recibimiento del Patriarca Afonso Mendes por el emperador abisinio, y en esa descripción se puede percibir una gran escenificación de la ceremonia organizada en la ocasión. Además, el padre Fernández habla de la conversión de los altos cargos del imperio como sucesos fuera de acontecimientos de sentido común. ${ }^{24}$ Ejemplos de referencias a acciones milagrosas como las mencionadas abundan también en las obras de Tomás de Barros.

-La segunda forma, según Zapunov, es la modalidad «polémico-dialógica», que da expresión a las eventuales polémicas y desavenencias entre los religiosos. No ha sido utilizada en todos los relatos, aunque es característica de documentos tales como la Historia de Etiopía del padre Pedro Páez Jaramillo, cuyo autor, por encargo de la Compañía de Jesús, pretendía desmentir las informaciones ofrecidas por el dominico Luis de Urreta sobre la realidad social, económica y cultural del reino del Preste Juan de las Indias (o Abisinia). La Historia eclesiástica y política de los grandes y remotos reynos de Etiopía, de Luis de Urreta, libro que provocó las polémicas anteriormente mencionadas, y Fundación, vida y regla de los Cavalleros Comendadores Monges, y Militares de la sagrada Orden del glorioso padre san Antón Abad en la Etiopía, monarchia del Preste Juan de las Indias, de Juan de Baltasar Abissino son libros donde abundan relaciones de hechos de carácter dialógico-polémico. Esta última obra, por ejemplo, presenta el imperio del

${ }^{22}$ P. Páez, op. cit., f.2r.

${ }^{23}$ D. de Matos, op. cit., f1v.

${ }^{24}$ D. de Matos, op. cit., f7v; A. Fernández, Copia de una del padre Antonio Fernández, Superior de las casas que la Compañía de Jesús tiene en el imperio de Etiopía, escrita en Dancas, corte del emperador de los abexinos en 11 de iunio de 1626, a su procurador en esta corte, del recibimiento que aquel emperador hizo al patriarcha católico, y de la reducción de aquel imperio a la iglesia romana, 1627, fol. 1v. 
Preste Juan de las Indias, o Etiopía, desde una perspectiva opuesta a la de los dominicos y de los jesuitas, pues sus argumentos pretenden contrarrestar las informaciones contenidas en los relatos de aquellos religiosos. En uno de los numerosos fragmentos polémicos de la obra de Juan de Baltasar Abissino se puede leer lo siguiente:

La Orden y religión que sólo florece en la Etiopía, y adonde muchos militares de Abadías y Conventos ay, es aquella del gloriosos y gran Patriarca S. Antón Abad. ${ }^{25}$

-La tercera forma es el modo «etnográfico», caracterizado por una acumulación y sistematización de informaciones sobre los pueblos y las regiones objeto de la evangelización. En nuestro caso los datos de carácter etnográfico contenidos en los relatos de los misioneros se han quedado en los límites de lo estrictamente necesario para dar cuenta del proceso de conversión de esos pueblos: ritos paganos en las prácticas religiosas, poligamia como régimen matrimonial, práctica de la hechicería son los elementos de la cultura negra apuntados y denunciados en este sentido. No obstante, está presente en la obra de Pellicer, pues el autor ha hecho una amplia descripción de la cultura de los negros en todos sus aspectos y sus manifestaciones.

-La cuarta forma, la «utópica», consiste en la narración o descripción de hechos desde la perspectiva de la estética religiosa, mediante la cual el escritor da rienda suelta a sus propias aspiraciones espirituales. Se encuentra poco asociada a la escritura de los misioneros.

A los modos indicados por Inés Zapunov, podemos añadir otros rasgos comunes a los relatos de los misioneros:

-La evocación del paisaje evangélico y la consideración de cada uno de los personajes implicados en las misiones como un alter-Cristo. Como se puede ver, se trata de alegorías o metáforas de origen bíblico.

-La concepción de las tierras de misión como «viñas» y de sus habitantes como «ovejas» llevó a los misioneros a considerarse como «obreros», u «operarios». Al referirse a sus actividades, esos religiosos hablaban de «trabajos» o de «empressas». Por otra parte, al asociar sus actividades misioneras con la salvación de las almas, imitaban a Cristo, o más bien, se convertían en cristos que sacrificaban sus vidas por el bien de los demás. La fiesta con que se marcaba la entrada de los misioneros en los pueblos y en las ciudades de las tierras de misión, en Etiopía y en el reino del Congo, parecía reproducir la propia entrada de Cristo en Jerusalén. Otro aspecto del mismo registro semántico es la asimilación de los misioneros a los peregrinos, un elemento que recuerda también la figura de Cristo y de los apóstoles.

Además de esos rasgos, en los relatos de los misioneros de la Compañía de Jesús y de la Orden de san Antón Abad, los religiosos se presentaban como soldados de Dios y adoptaban términos propios al ejército, como «general», «compañía», «capitán» etc. La trayectoria formativa de sus miembros, la jerarquía de poderes que regía sus órdenes y la disciplina férrea que caracterizaba esas estructuras son otros aspectos bien reflejados en los relatos de los misioneros jesuitas y que recuerdan la organización de un ejército.

${ }^{25} \mathrm{~J}$. de Baltasar Abissino, Fundación, vida y regla de los Cavalleros Comendadores Monges, y Militares de la sagrada Orden del glorioso padre san Antón Abad en la Etiopía, monarchia del Preste Juan de las Indias, fol. 1r. 
Desde el punto de vista estilístico y temático, las obras de los misioneros se caracterizan por unos topos o locus communis que consisten en repertorios de argumentos generales. Todas las narraciones y descripciones se han orientado hacia la búsqueda de circunstancias que permitían desarrollar los mismos temas. El topos narrativo en esas obras consiste en un relato recurrente de elementos pertinentes, temáticos o formales. Como configuración o combinación narrativa actúa como mini-esquema que orienta la escritura de todos los religiosos. Dentro de este topos, también son recurrentes muchos topoi, tales como los cismáticos que se convierten a la religión católica y la sirven con devoción, los hechiceros que abandonan sus hechizos bajo la influencia y la acción milagrosa de los misioneros y se vuelven buenos cristianos, los idólatras que adoran la cruz de Cristo y la imagen de la Virgen María en detrimento de sus ídolos, los musulmanes enemigos de la fe cristiana que se vuelven bondadosos con los misioneros durante sus viajes.

Entre los relatos del siglo XVII se singulariza la obra de José Pellicer de Ossau Salas y Tovar, Missión evangélica al reyno del Congo por la seráfica religión de los Capuchinos. Además de tener todos los rasgos señalados en los relatos de los misioneros, contiene unos elementos importantes que la clasifican en una subcategoría un poco distinta de los relatos de los misioneros viajeros. Las particularidades más relevantes de esta última obra, residen en estos aspectos: el autor es un seglar, aunque la historia de la obra se desarrolla en torno a la misión de los Capuchinos en el reino del Congo. Además, el autor no realizó el viaje que constituye la urdimbre del relato, sino que se basó en las informaciones que le trasmitió uno de los protagonistas de esa misión evangélica, fray Ángel de Valencia, y en el relato de otro misionero, fray Juan Francisco de Roma. Por otra parte esta obra es la más extensa de todos los relatos del siglo XVII analizados, precisamente por la diversidad de los temas tratados en ella y la combinación de los modos de escritura ya señalados en los relatos de los misioneros. Además, y al contrario de los misioneros, José Pellicer ha usado ampliamente el modo etnográfico en su obra sobre el reino del Congo, dedicando casi veintiocho folios a la descripción del Congo en todos sus aspectos (geografía física y humana). ${ }^{26}$ También se puede notar un buen uso de la cuarta modalidad de la escritura que señalaba Inés Zapunove, la forma que se caracteriza por la estética religiosa, pero en proporciones relativamente pequeñas, como este ejemplo:

Ésta fue una de las maravillas de Dios, i que la corta semilla evangélica que se derramó en esta provincia por espacio de ciento i cinquenta años, casi sin cultura, sin riego, sin sacerdotes i sin obreros, aya permanecido firme, creciendo i dando fertilíssima cosecha en la África quando acá en la Europa a vista de la christiandad toda i en el centro della, vacilaron i cayeron tantas i tan bien fundadas colunas de templo militante de la iglesia. Bolved los ojos, pues, pérfidos heresiarcas, al reyno de Congo; reconoceréis la rara mutación de semblantes en la religión. Vosotros con cuerpos blancos i almas negras, i ellos con cuerpos negros i almas blancas de albadas en la sangre inocente de cordero. ${ }^{27}$

\footnotetext{
${ }^{26}$ J. Pellicer de Tovar, Missión evangélica al reyno del Congo, op. cit., fols. 47-74.

${ }^{27}$ J. Pellicer de Tova, op. cit., fol 15 r.
} 


\subsection{Distribución de los relatos de viajes dentro del espacio negroafricano y la influencia del componente mítico}

La distribución geográfica de esos relatos de viajes dentro del espacio del África negra apunta a un incremento del interés de los viajeros del siglo XVII por el imperio abisinio o Etiopía. Todos los relatos del siglo XVII sobre el África negra, con excepción de Missión evangélica al reyno del Congo, versan sobre Etiopía. Esa atracción que ejercía Abisinia en los Occidentales pudo deberse a varios factores tanto mitológicos, históricos como espirituales, pero sobre todo a los peculiares aspectos de la sociedad Abisinia. Ese reino destacaba por la singularidad de su historia sociopolítica, hecha de auténtica mezcla entre mitos y realidades, entre los cuales cabe recordar los siguientes elementos: los factores mitológico, espiritual, cultural e histórico. ${ }^{28}$

\subsubsection{El factor mitológico}

El mito de la emperatriz es el elemento fundamental en este sentido. La historia de Etiopía se ha construido sobre el mito de que sus emperadores descienden del rey Salomón. Según la leyenda, la reina de Saba, emperatriz de Etiopía, viajó a Jerusalén para conocer al sabio rey Salomón, del que concibió un hijo, que gobernaría años más tarde con el nombre de Menelik. La Biblia, Reyes I, 10, describe la visita de la reina de Saba al rey Salomón, diciendo que quedó admirada de su sabiduría y le obsequió con gran cantidad de oro, aromas y piedras preciosas. Este elemento podía constituir por sí solo un motivo de admiración por ese reino y un estímulo válido para emprender viajes a ese imperio.

Otro elemento del mismo registro semántico es la leyenda del Preste Juan. Tras las búsquedas frustradas del mítico y fabuloso reino cristiano del Preste Juan desde el año 1249 aproximadamente, tan grande fue la curiosidad por conocer ese reino que, en la segunda mitad del siglo XIV, la atención se centró en Abisinia (como se puede comprobar en la obra de Luis del Mármol Carvajal ${ }^{29}$ ), y se creyó que el Preste Juan podía ser el rey cristiano de aquel país africano lindante con el mar Rojo. La aparición de la obra de Francisco Alvares, Verdadeira descripçam das terras do Preste João das Indias en 1520, en la que el autor desmentía en parte las Mirabilia atribuidas a ese reino podía haber restado importancia a ese elemento mitológico, pero a pesar de ello se relanzó el debate sobre la naturaleza de ese supuesto reino cristiano perfecto y fabuloso con la publicación de las

\footnotetext{
${ }^{28}$ Además de los relatos de viajes de los siglos XVI y XVII sobre el África negra, que tratan ampliamente la originalidad de la sociedad abisinia, por la especificidad y la complejidad de su historia sociopolítica y cultural, se puede consultar también las obras de Javier Reverte, Dios, el Diablo y la aventura, op. cit; Hervé Pennec, Des jésuites au royaume du Prêtre Jean (Ethiopie), Paris : Fondation Calouste Gulbenkian, 2003; « La Misión jésuite en Ethiopie au temps de Pedro Paez (1583-1622) et ses rapports avec le pouvoir éthiopien », Rassegna di Studi Etiopici, 36 (1994), pp. 77-115 ; 37 (1995), pp. 135-165 ; 37 (1996), pp. 139-181; « La correspondance royale éthiopico-européenne de 1607 », Cahier du Centre de Recherches Africaines, 9 (1998), Bertrand Hirsche, Connaissance et figures de l'Ethiopie dans la cartographie occidentale du XIV siècle au XVI ${ }^{e}$ siècle, (Tesis Doctoral), Paris : Université de Paris I, 1991, pp. 520-521.

${ }^{29}$ C. F. Beckingham, «European sources for Ethiopian History befote 1634» Paideuma, 33 (1987), pp. 167-178.

${ }^{30}$ P. Caraman, L'empire perdu: l' histoire des jésuites en Éthiopie, Paris : Desclée de Brouwer, 1988.

${ }^{31}$ Sobre este aspecto, remito a mi tesis doctoral, África negra en los libros de viajes..., op. cit., pp. 183-191.
} 
dos obras del misionero dominico, el padre Luis de Urreta y, así, Etiopía volvía a atraer a viajeros, misioneros y curiosos. Todos esos elementos podían justificar el interés creciente en el tratamiento del tema de Etiopía en los relatos de viajes de esa época.

\subsubsection{El factor espiritual y cultural}

La sociedad abisinia se caracterizaba por una cultura y civilización especiales dentro del África negra. La leyenda de la aventura amorosa de la reina de Saba y el rey Salomón surtió efectos en la civilización etíope, pues esa leyenda ayudaba a explicar la presencia de elementos judíos en la cultura etíope, como la circuncisión, la observancia del sábado, la pureza legal y la construcción de iglesias siguiendo el modelo del templo de Jerusalén. Descubrir y observar tales particularidades podían ser otro motivo para emprender viajes a Etiopía.

Además, la temprana cristianización del imperio es otro elemento característico de abisinia, desde el punto de vista religioso. El origen del cristianismo en Etiopía se remonta al siglo IV, cuando dos comerciantes sirios cristianos, Frumencio y Edesio, convirtieron al rey abisinio Ezana. El rey Ezana declaró el cristianismo religión oficial de su imperio, otorgó tierras y privilegios a la Iglesia y acuñó la cruz en las monedas de su reino, un hecho que sucedía por primera vez en la historia. Ese aspecto convertía a Etiopía y a los etíopes en objeto de gran admiración también. Pero el cristianismo abisinio era original, pues a pesar de su antigüedad, ese cristianismo presentaba rasgos que lo convertía en un cristianismo original, y tal vez herético, como decían los misioneros del siglo XVII. La Iglesia de Alejandría, tras el Concilio de Calcedonia, en el año 451, rompió con la Iglesia de Roma. Los representantes de la Iglesia de Alejandría y Constantinopla defendían que la naturaleza de Cristo era sólo una y divina, concluyendo que Jesucristo es Dios, pero no hombre. Esta afirmación de los llamados monofisitas fue declarada herética por la Iglesia de Roma. Sabiendo que Etiopía era un bastión importante de ese cristianismo, ese reino debía ser considerado como una prioridad entre las tierras de misión y el objetivo era lograr la obediencia de ese imperio a Roma. De ahí el gran interés manifestado por los religiosos por ese imperio.

\subsubsection{El factor histórico}

Abisinia tiene una historia construida sobre un mito: el Arca de la alianza. La leyenda dice que Menelik, hijo de la reina de Saba, viajó a Jerusalén para conocer a su padre, el rey Salomón. Al concluir la visita y regresar a su país, los sacerdotes que custodiaban el Arca de la Alianza la robaron del templo y, escondida entre la comitiva de Menelik, la trajeron a Aksum, la capital del imperio abisinio. El Arca de la Alianza habría sido instalada en un templete dentro del recinto del palacio real y custodiada día y noche por sacerdotes, sin que nadie la pudiera ver porque, según la creencia, quien la viera moriría. Ese elemento fue presentado también como prueba de que los abisinios son descendientes directos del rey Salomón.

A todos esos aspectos, habría que añadir un factor también determinante para explicar el gran interés de los españoles por Etiopía, que tiene sus raíces profundas en la sim- 
bología de ese reino en la cultura medieval, perpetuada a través de los siglos. Se trata de la posición estratégica de ese imperio, el único territorio cristiano en medio de varios reinos musulmanes, único punto desde el que los Occidentales en general, y los españoles en particular, podían posicionarse para contrarrestar la progresión del amenazador poderío del reino otomano, en el África negra. Todo ello y, sobre todo, el factor religioso evocado arriba, motivaron el flujo de los viajeros, y principalmente de los misioneros de diversas órdenes religiosas a Etiopía.

Por último, señalemos otro rasgo diferencial, tal vez el más significativo entre los autores de los libros de viajes del siglo XVI y los religiosos del siglo XVII que queda plasmado en su actitud ante la expresión de la alteridad asociada a la cultura negra, y más precisamente a la lengua. La lengua, como fenómeno comunitario equiparable a cualquier otra costumbre, es un rasgo que permite definir la identidad en términos de diferencia y afinidad entre los pueblos y, así, constituye un elemento de referencia en el discurso etnográfico. Pero las referencias a las lenguas de las tierras de los Negros son prácticamente inexistentes en los dos importantes relatos de viajes del siglo XVI sobre el África negra. Esa ausencia cobra sentido en la medida en que se convierte en uno de los modos en que esos autores intentaban presentar la homogeneidad lingüística de los pueblos y las tribus del África negra, o lo ininteligible de su lengua. Juan León el Africano y Luis del Mármol Carvajal, en sus respectivas obras, afirmaban que la mayoría de esos africanos no tenían nombres propios: otro rasgo que, junto con la ininteligibilidad de la lengua, demostraba la barbarie de los Negros, su extremo primitivismo expresado por el total anonimato de los habitantes. Con los misioneros, en cambio, se marca un hito importante en la consideración de la cultura negra, sobre todo a través del elemento fundamental de esa cultura, la lengua. Los religiosos no sólo reconocieron las lenguas africanas en sus escritos sino que se apoyaron en ese elemento para lograr su objetivo. Al llegar a las tierras de misión, los misioneros aprendían primero las lenguas locales para facilitar la comunicación con los lugareños. Así, los jesuitas del imperio abisino aprendieron las dos lenguas importantes de Abisinia: el amárico y el gue'ez. Algunos de ellos llegaron a escribir obras literarias en esas lenguas. ${ }^{30}$ Más allá del carácter utilitario del reconocimiento y del aprendizaje de esos idiomas, el conocimiento lingüístico ayudó a esos religiosos a aprehender mejor el funcionamiento de las sociedades y de las culturas negras, así como los códigos que las regían. Como prueba de ese buen entendimiento de la realidad negra, los misioneros en sus obras, daban casi siempre los nombres de las realidades culturales o de los personajes, puestos administrativos o rango dentro del ejército en lengua africana local, seguidos de la traducción española. Además de ser prueba del buen conocimiento de esos idiomas locales, esos elementos lingüísticos permitieron a los religiosos ahondar en la comprensión de las culturas negras. Todo ello, cabe recalcar, supone contactos más estrechos entre esos misioneros y las poblaciones negras en todos sus estratos sociales, en claro contraste con la actitud de distanciamiento que caracterizaba las relaciones de los viajeros del siglo XVI, tales como Juan León el Africano y Luis del Mármol Carvajal, con las poblaciones negras. Con todo, la razón definitiva que explica

\footnotetext{
${ }^{32}$ Muestra de ello nos la ofrecen los libros de Antonio Fernández, Magsêf Assetat, id est Flagellum Mendaciorum, Goa: [s.n], 1642, Biane Cassaust (manuscrito) y Abbau Haymonot, [s.n], escritos en amarico, una lengua de Abisinia.
} 
esa diferencia entre los escritores seglares del siglo XVI y los misioneros del siglo XVII en el tratamiento de las informaciones sobre el espacio y la representación de las poblaciones del África negra era esencialmente estratégica.

\section{Puntos de CONFluencia entre los Relatos Del Siglo XVI y DEl Siglo XVII}

Existen unos cuantos puntos comunes entre los relatos del siglo XVI y los de los religiosos, correspondientes al siglo XVII, sobre el África negra. En primer lugar, todos esos relatos contienen componentes milagrosos o maravillosos, aunque la amplitud, el significado y la extensión de esos aspectos no son los mismos para los misioneros y los seglares. Además, todos esos relatos ofrecen micro-secuencias que tienen muchos puntos en común con el género hagiográfico, ampliamente desarrollado desde tiempos atrás, con propensión a un gusto por los sucesos prodigiosos y la reiteración de las formas narrativas de los episodios más exóticos; si bien esos aspectos se encuentran más desarrollados en los relatos del siglo XVI.

La intertextualidad es otro punto común a todos esos relatos sobre el África negra, pues recogen y enfocan desde diferentes prismas muchos temas relacionados con las cualidades de los hombres y de las tierras de los negros: la mítica figura del Preste Juan de las Indias, el abrasador calor característico de la tierra de los negros, la monstruosidad de sus pueblos según el ángulo desde el que el autor los ve etc.

\section{CONCLUSIÓN}

El análisis de los contenidos geográficos, históricos, antropológicos y culturales de los libros de viajes españoles de los siglos XVI y XVII sobre el África negra ha permitido observar que el discurso de los autores del siglo XVI se integraba en el discurso científico medieval en general, y por tanto, constituía una prolongación de esa época. Entre los rasgos fundamentales de los libros científicos medievales conservados en las obras de Juan León el Africano y Luis del Mármol Carvajal, se puede citar la fidelidad con respecto a las fuentes antiguas, que engendra a veces una tensión entre la ciencia empírica y la ciencia literaturizada. Aunque esos libros no son imaginarios, han integrado demasiados datos compilados a partir de fuentes librescas que proponían un universo geográfico con predominio de lo maravilloso y de lo fantástico. La intención informativa inicial de esos autores sufrió un deslizamiento progresivo desde lo informativo hacia lo ficticio a través del recurso a lo maravilloso y fantástico, rasgos que constituyen una dimensión muy importante de la literariedad de esos relatos de viajes. Al mismo tiempo, estos aspectos atenúan, si no desmienten totalmente, la creencia generalmente aceptada de que esos libros de viajes pecan por la redundancia de su realismo intrínseco y su carencia en aspectos literarios. Los relatos del siglo XVII, en cambio, integran bastantes informaciones de carácter antropológico, histórico y cultural y menos elementos maravillosos. Otros rasgos que constituyen pruebas de la literariedad tanto de los libros de viajes del siglo XVI como de los relatos de los misioneros del siglo XVII tienen que ver con el uso de las secuencias retóricas, estilísticas y tópicas, elementos que ya mencionamos al hablar 
de las diferentes maneras en que esos escritores presentaban informaciones de carácter documental sobre el África negra y sus habitantes.

\section{BIBLIOGRAFÍA}

\section{LIBROS DE VIAJES ESPAÑOLES DE LOS SIGLOS XVI Y XVII SOBRE EL ÁFRICA NEGRA}

ABISSINO, Juan de Baltasar. Fundación, vida y regla de la grande orden militar y monástica de los cavalleros y monjes del glorioso padre san Antón Abad, en la Etiopía, Monarchia del Preste Juan de las Indias, Valencia: [s. n], 1609.

AFricano, Juan León El. Descripción general de África y de las cosas peregrinas que allí hay, Roma: Ramusio, 1550. Precisemos que en este trabajo manejamos la edición de Serafín Fanjul Descripción general de África y de las cosas peregrinas que allí hay, Barcelona: Lunwerg, 1995.

ÁlvAREs, Francisco. Verdadeira informaçam das terras do Preste João das Indias, Lisboa: Imprensa Nacional, 1889.

BARros, Tomás de. Copia de una carta que escrivió el padre Tomás de Barros de la Compañía de Iesus en Iunio de 622 al padre General, en que declara lo que los de la Compañía hizieron en el imperio de Etiopía, en el dicho año de 622.

D'AlmeIDA, Manoel. Historia de Ethiopia a alta ou Abassia, imperio do Abexim, cujo Rey hé chamado Preste Joam, composta pelo padre Manoel d'Almeida da Companhia de Jesus, natural de Viseu, ..., 1611.

FERnÁNDEZ, Antonio. Copia de una del padre Antonio Fernández, Superior de las casas que la Compañía de Jesús tiene en el imperio de Etiopía, escrita en Dancas, corte del emperador de los abexinos en 11 de iunio de 1626, a su procurador en esta corte, del recibimiento que aquel emperador hizo al patriarcha católico, y de la reducción de aquel imperio a la iglesia romana, Madrid: Viuda de Luis Sánchez, 1627.

Mármol Carvajal, Luis del. Descripción general de Áffrica: Primera Parte, Granada: René Rabut, 1573. La edición que se ha manejado es la facsímil del Instituto de Estudios Africanos del Patronato Diego Saavedra Fajardo del Consejo Superior de Investigaciones Científicas, 1953.

-, Segunda parte y libro séptimo de la descripción general de Áffrica, donde se contiene las provincias de Numidia, Libia, la tierra de los Negros, la baxa y la alta Etiopía, Egipto, con todas las cosas memorables della, Málaga: Iuan René, 1599.

Matos, Diego de. Copia de una carta que el padre Diego de Matos de la Compañía de Iesus escrive al padre General de la misma Compañía, en que da quenta a su paternidad del estado de la conversión a la verdadera religión christiana católica romana, del gran imperio de Etiopía, cuyo emperador es el Preste Juan, escrita en la ciudad de Fremona, su fecha en veinte de iunio de 1621, Madrid: Luis Sánchez, 1624.

Páez Jaramillo, Pedro. Copia de una carta del padre Pedro Páez de la Compañía de Jesús, escrita en Etiopía por Iulio del año passado, para un padre de la misma Compañía de la Provincia de Toledo. En la qual le da cuenta de cómo el emperador de aquel reyno se a buelto cristiano, y de una gran vitoria que alcançó de un hermano suyo, que le quería matar por aver dexado entrar el Santo Evangelio en sus tierras, Sevilla: Francisco de Lira, 1619.

- Copia de una del padre Pedro Páez de la Compañía de Iesus, escrita en Etiopía a 6 de iulio de 617 para un padre de la provincia de Toledo de dicha Compañía, [s. n]

PAIs, Pero. Historia de Etiópia, edición, introducción y notas de Elaine Sanceau, Porto: Livraria e Civilização, 1945. 
Pellicer de Ossau Salas y Tovar, José. Mission evangelica al reyno de Congo por la Seráfica religión de los capuchinos, Madrid: Domingo García Morrás, 1649.

Tellez, Baltasar. Histoira geral de Ethiopia a Alta ou Abassia do Preste Ioam, e do que nella obraram os padres da Companhia de Iesus: composta no mesma Ethiopia, pelo padre Manoel d'Almeyda, natural de Viseu, Provincial, e Visitador, que foy na India. Abreviada como nova releyçam, e methodo pelo padre Balthazar Tellez, natural de Lisboa, Provincial da Provincia Lusitana, ambos da mesma Companhia, Coimbra: Manuel Dias, 1660.

URRETA, Luis de. Historia eclesiástica, política, natural y moral de los grandes y remotos reynos de Etiopía, Monarchia del Emperador, llamado Preste Juan de las Indias. Muy útil y provechosa para todos estados, principalmente para predicadores. A la sacratísima y siempre Virgen María del Rosario. Compuesta por el Presentado Fray Luis de Urreta, de la Sagrada Orden de Predicadores, Valencia: Pedro Patricio Mey, 1610.

—, Historia de la sagrada Orden de los predicadores en los remotos reynos de la Etiopía. Trata de los prodigiosos Santos, Mártyres, y Confessores, Inquisidores apostólicos, de los conventos puritanos, donde viven nueve mil frayles del alleluya con siete mil de los Bedenagli, de cinco mil monjas, con otras grandesdezas de la religión del padre santo Domingo, Valencia: Juan Chrysostomo Garriz, 1611.

\section{BIBLIOGRAFÍA CONSULTADA}

BARANDA LETURIO, Nieves. «Los libros de viajes en el mundo románico», en Revista de Literatura Medieval, V (1993), pp. 295-302.

—, «El espejismo del Preste Juan de las Indias en su reflejo literario en España» en A. Vilanova (ed.), Actas del X Congreso de la Asociación Internacional de Hispanistas (agosto 1989).

Barbosa MACHADO, Diego. Bibliotheca Lusitana historica, critica e cronologica: na qual se comprehende a noticia dos autores portugueses...desde o tempo da promulgação da ley de graça até o tempo prezente, Lisboa: Officina de Antonio Isidoro da Fonseca, 1747.

Beckingham, Charles F. «European sources for Ethiopian History befote 1634» Paideuma, 33 (1987), pp. 167-178.

Bouba KIDAKOU, Antoine. África negra en los libros de viajes españoles de los siglos XVI y XVII (tesis doctoral), Madrid: UNED, 2006.

BOUCHER, Adolfo. Historia de los jesuitas: descripción dramática de sus viajes, conquistas y misiones, y de los adulterios, asesinatos, regicidios, envenenamientos y demás crímenes cometidos o instigados por la Compañía de Jesús, desde la fundación de la orden hasta nuestros días, Barcelona: José Codina, 1870.

BunES IBARRA, Miguel Ángel de. La imagen de los musulmanes y del Norte de África en la España de los siglos XVI y XVII, Madrid: CSIC, 1989.

CARAMAN, Philip. L'empire perdu: l' histoire des jésuites en Éthiopie, Paris : Desclée de Brouwer, 1988.

—, The lost empire (the story of the jesuits in Etiopía, 1555-1634), Londres: Sidwick \&Jackson, 1985.

Cencillo de Pineda, Manuel. Etiopía, el reino del Preste Juan y del trono de David, Madrid: Artes Gráficas FÉNIX, 1960.

FANJUL, Serafín. «Introducción», en Juan León el AFRICANO (ed.) de S. Fanjul, Barcelona: Lunwerg, 1995.

García-Romeral, Carlos. Bio-bibliografía de viajeros españoles (siglos XVI-XVIII), Madrid: Ollero \& Ramos, 1997.

—, Diccionario de viajeros españoles. Desde la Edad Media a 1970, Madrid: Ollero y Ramos, 2004. 
Herrero Mediavilla, Víctor y Aguayo Nayle, L. Índice biográfico de España, Portugal e iberroamérica, Paris: Saur, 1990.

HIRSCHE, Bertrand. Connaissance et figures de l'Ethiopie dans la cartographie occidentale du XIV siècle au XVI siècle, (Tesis Doctoral), Paris : Université de Paris I, 1991.

LEITE, Serafim. Cartas dos primeiros jesuitas do Brasil, São Paulo: Comissão do IV Centenario da Cidade de São Paulo, 1954.

PALOMo, Federico. «De algunas cosas que sucedieron estando en misión. Espiritualidad jesuita y escritura misionera en la Península Ibérica (siglos XVI-XVIII)» en A Compañía de Jesús na Peninsula Iberica nos seculos XVI e XVIII, Actas do Coloquio Internacional, Porto: Humbertipo, 2004.

PenNeC, Hervé. «La Misión jésuite en Ethiopie au temps de Pedro Paez (1583-1622) et ses rapports avec le pouvoir éthiopien», Rassegna di Studi Etiopici, 36 (1994), pp. 77-115 ; 37 (1995), pp. 135-165; 37 (1996), pp. 139-181.

—, «La correspondance royale éthiopico-européenne de 1607», Cahier du Centre de Recherches Africaines, 9 (1998), p. 24.

—, Des jésuites au royaume du Prêtre Jean (Ethiopie), Paris : Fondation Calouste Gulbenkian, 2003

ReVERTE, Javier. Dios, el diablo y la aventura, Madrid: Plaza \& Janés, 2001

RUSSEL, P. E. «Veni, vidi, vinci: some fifteenth century eyewitness accounts of travel in the African Atlantic before 1492» in Historical Research, 66 (160), 1993, pp. 115-128.

TORRES LONDOÑo, Fernando. «Escrevendo Cartas. Jesuitas, escrita e Missão no século XVI» en Revista Brasileira de Historia, 43 (2002), pp. 17-18.

ZAPUNOv, Inés. Disputed Misión. Jesuit Experiments and Brahmanical Knowledge in Seventeenthcentury India, New-Delhi: 1999. 